\title{
Numerical study of effect of elastomeric stress absorbers on stress reduction in bone-dental implant interface
}

\author{
Ghalem MEHDI' ${ }^{1}$ Abderrahmane BELARBI ${ }^{1}$, Bensmaine MANSOURI' ${ }^{1}$, Zitouni AZARI ${ }^{2}$ \\ 1- Department of Mechanical Engineering, University of Science and Technology, Oran, Algeria. \\ 2- Laboratory of Biomechanics, Polymers and Structures, ENIM-Metz, France. \\ Corresponding address: Abderrahmane Belarbi - Faculty of Mechanical Engineering - USTO MB - BP1505 El Mnaouer - Oran - Algeria - Phone: (213)791310914 \\ - e-mail: belarbi_abd@yahoo.fr
}

Submitted: April 3, 2014 - Modification: November 1, 2014 - Accepted: December 3, 2014

\section{ABSTRACT}

\begin{abstract}
$\mathrm{O}$ bjective: This paper focused on optimal stress distribution in the mandibular bone surrounding a dental implant and is devoted to the development of a modified Osteoplant ${ }^{\circledR}$ implant type in order to minimize stress concentration in the bone-implant interface. Material and Methods: This study investigated $0.4 \mathrm{~mm}$ thick layers of two elastomeric stress barriers incorporated into the dental implant using 3-D finite element analysis. Results: Overall, this proposed implant provoked lower load transfer in boneimplant interface due to the effect of the elastomers as stress absorbers. The stress level in the bone was reduced between $28 \%$ and $42 \%$ for three load cases: $75 \mathrm{~N}, 60 \mathrm{~N}$ and $27 \mathrm{~N}$ in corono-apical, linguo-buccal and disto-mesial direction, respectively. Conclusion: The proposed model provided an acceptable solution for load transfer reduction to the mandible. This investigation also permitted to choose how to incorporate two elastomers into the Osteoplant ${ }^{\circledR}$ implant system.
\end{abstract}

Keywords: Dental implants. Bone. Masticatory force. Elastomers. Finite element analysis.

\section{INTRODUCTION}

Stress concentrations levels in the rigid interface between the dental implant and the adjacent bone are different compared to the tooth/bone system, where the presence of periodontal ligament serves as hyper-viscoelastic interface ${ }^{3,21,24}$. Works in this direction located high stress levels compared to the natural tooth/bone system in the implant neck region $9,25,26$, causing painful conditions in the jaw bone ${ }^{15,17,20}$ and resulting from masticatory forces. To overcome these disadvantages, some researchers have proposed models with accessories such as the intra mobile element ${ }^{2}$, the elastic collar around the neck of the implant ${ }^{1}$, or even an artificial ligament ${ }^{7}$, while other approaches have attempted geometric modifications to optimize implant design according to their biomechanical performance ${ }^{5,6,13,18,29}$. Biologically, the interface is constituted by the osseointegration phenomenon of the bone regeneration, which tends to fill the gap in the bottom of the implant thread ${ }^{12}$. The effect of periodontal ligament in the natural system has originated the idea for an investigation to introduce two elastomers in implant component interfaces judiciously selected, to break the load transfer from the implant to the bone. The objective of this study is based on the comparison of the stress levels in two different Osteoplant ${ }^{\circledR}$ implant types under the same loading conditions in order to assess the benefits of the modified dental implant with three load cases transferred to the surrounding bone media using finite element method. The first is conventional while the second is modified by the introduction of $0.4 \mathrm{~mm}$ thick layers of two elastomers (silicone) as bio-inert stress absorbers; one is interposed between the abutment and the implant, while the other covers the head of the screw fixing the abutment. This new design led to a new proposed model. Over the last few years, computer simulation applied to biomechanics has become an extremely useful tool for numerically 
assessing stresses associated with mechanical behavior of biomaterials and human tissues.

\section{MATERIAL AND METHODS}

An Osteoplant ${ }^{\circledR}$ dental implant type, manufactured in the early 1990 s by a team of dentists at the Medical University in Poznan (Poland) was chosen for this study. Figure 1 presents the full Osteoplant ${ }^{\circledR}$ system screwed and osseointegrated in jaw bone in rigid contact while the abutment is connected to the implant by conical contact and screwed. The mandibular bone is modeled as a cancellous bone surrounded by the cortical bone. The Osteoplant ${ }^{\circledR}$ components are specified with global dimensions. The full models were assembled using the Solid Works software and exported to Ansys Workbench finite element code.

Mastication can be assumed as normal and lateral dynamic cyclic loads on the upper crown area. This implies a fatigue study to determine alternating stress effect on dental implants lifespan. However, several works have been conducted under static loading conditions to study the effects of the geometric parameters on the stress levels in the bone $3,5,11,12$.

The boundary conditions are defined in Figure 2:

The side faces of the mandible are assumed fixed;

The other surfaces are treated as free surfaces;

The static masticatory forces are considered in three directions on the upper surface of the crown;

The distributed load over this area is calculated using the formula: where: $\quad \sigma_{a}(M P a)=\frac{F(N)}{S\left(m m^{2}\right)}$

$\sigma_{a}$ : applied distributed load.

$F$ : normal or bending masticatory force in the specified direction.

S: upper area of the crown.

The three load cases are defined in Table 1.

The interfaces between different parts of the implant-bone system are assumed to be bonded, with the exception of the screw head-elastomer interface, which is treated as frictional contact. The screw head, which fixes the abutment to the implant and compresses elastomer 1 , must not be fully bonded with elastomer 2 when the vertical and lateral displacement of the abutment occurs, in order to break continuity of screw-abutmentimplant stiffness. For this purpose, a frictional coefficient with sufficient value $f=0.19$ was chosen at this interface to ensure this role.

The bone, a living tissue containing both cortical and cancellous parts, is neither homogeneous nor isotropic ${ }^{14}$. As the cortical part exhibits better resistance than the cancellous one, the bone is often regarded as linear elastic, homogeneous and isotropic, as widely adopted in the existing literature ${ }^{8,10}$. In this study of the dental implant system, all materials are assumed linear elastic. The material properties are summarized in Table 2.

As shown in Figure 3, all system components were meshed with tetrahedral quadratic elements. Node and element numbers are given in Figure 4. Since the bone-implant interface is the most interesting region, mesh refinement in this area is required to achieve acceptable accuracy, so both
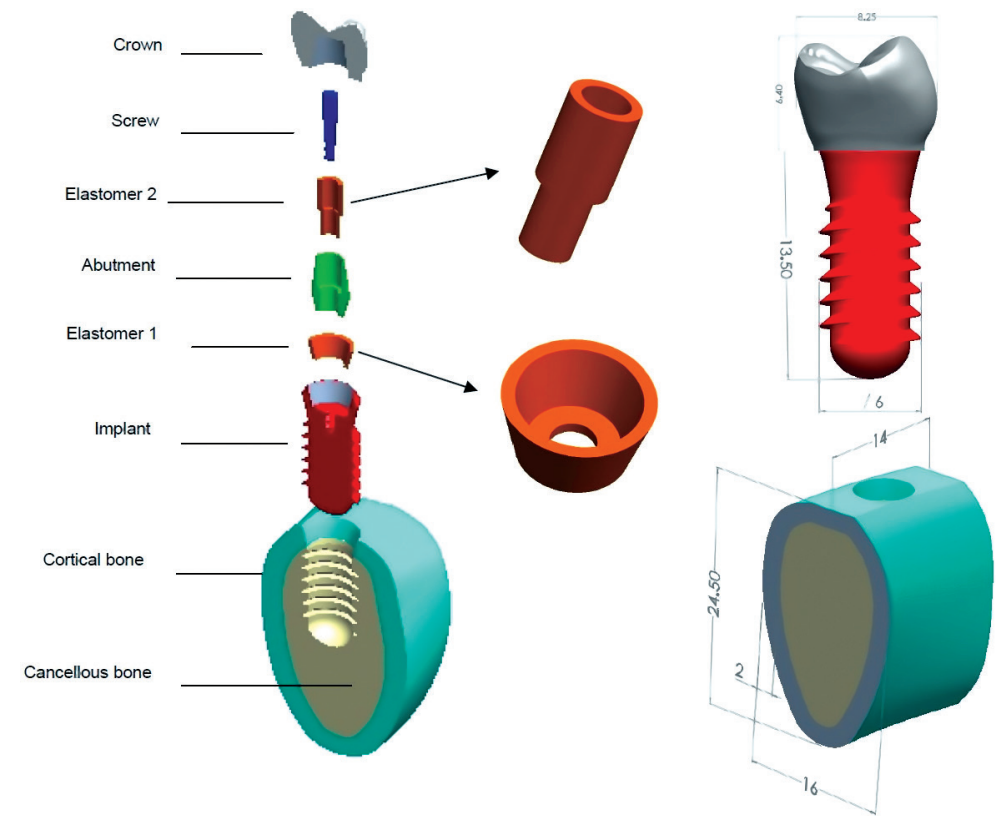

Figure 1- Components of an Osteoplant ${ }^{\circledR}$ implant model with two incorporated elastomeric stress absorbers with global data form 
conventional and elastomeric implant models are numerically computed using three loading cases.

\section{RESULTS}

In this study, von Mises stress was selected because of the complexity of the bone shape. The resulting von Mises stress values, computed in the components of the two systems under the three load cases effect are shown in Figures 5 and 6.

This study is based primarily on stress level values in the mandibular bone. For this purpose, von Mises stress analysis was calculated for all components of the two systems in the three loading cases. Then, a comparison of results was compiled to see the proposed elastomeric model advantage compared to the conventional one. All results are gathered in Table 3. Therefore, histograms are established for stress levels in bone, abutment, implant and crown for each load type in Figure 7.

This analysis shows that for both conventional and elastomeric models, the maximum von Mises stress levels located in the cortical bone under the three load cases are in the contact area with the implant neck. Figure 7 reflects stress level variations under different load cases and clearly indicated the effect of elastomers. The decrease of stress value in the bone with the modified implant model is due to the incorporation of two elastomers into the implant-abutment and abutment-screw head interfaces to generate a barrier for the stiffness system continuity. The reduction of stress

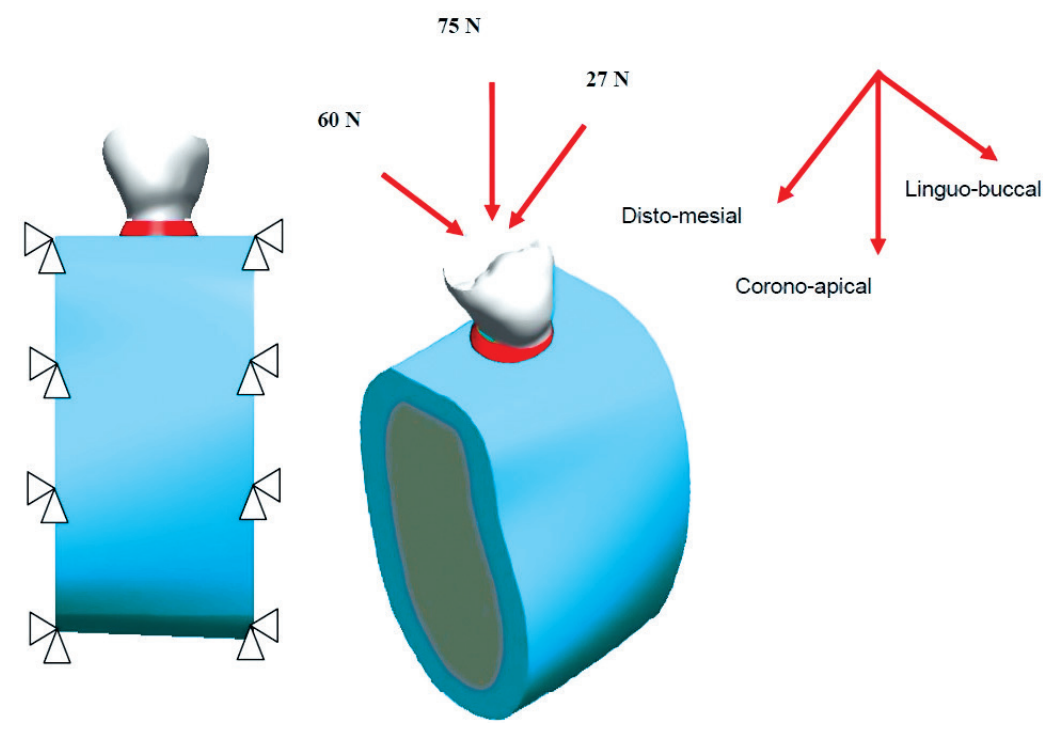

Figure 2- Boundary conditions of the mandible and loading types

Table 1- Applied load values in the specified directions

\begin{tabular}{ccccc}
\hline Load case & Corono-apical & Linguo-buccal & Disto-mesial & S: upper crown area \\
\hline $\mathrm{F}(\mathrm{N})$ & 75 & 60 & 26 & $47.23 \mathrm{~mm}^{2}$ \\
$\sigma a(\mathrm{MPa})$ & 1.58 & 1.27 & 0.55 & \\
\hline
\end{tabular}

Table 2- Mechanical properties of implant model components

\begin{tabular}{|c|c|c|c|c|c|c|c|}
\hline Component & Material & Property & $\begin{array}{c}\text { Young's } \\
\text { modulus } \\
\text { (GPa) }\end{array}$ & $\begin{array}{l}\text { Poisson's } \\
\text { ratio }\end{array}$ & $\begin{array}{c}\text { Tensile } \\
\text { stress (MPa) }\end{array}$ & $\begin{array}{c}\text { Strenght } \\
\text { stress (MPa) }\end{array}$ & Ref. \\
\hline Crown & $\mathrm{Co}-\mathrm{Cr}$ & \multirow{5}{*}{$\begin{array}{c}\text { isotropic } \\
\text { linear elastic }\end{array}$} & 218 & 0.33 & 450 & 655 & 16 \\
\hline $\begin{array}{l}\text { Abutment } \\
\text { Screw } \\
\text { Implant }\end{array}$ & $\begin{array}{l}\text { Titanium } \\
\text { alloy }\end{array}$ & & 110 & 0.3 & 880 & 950 & 15.19 \\
\hline Elastomers & Silicone & & 0.006 & 0.49 & - & $20-30$ & 17 \\
\hline \multirow[t]{2}{*}{ Bone } & Cortical & & 14.5 & 0.323 & $50-190$ & - & 11 \\
\hline & Cancellous & & 1.37 & 0.3 & $\sim 30$ & - & 12.13 \\
\hline
\end{tabular}


concentration in the contact region of the neck implant with the cortical bone depends of the load type. The stress decrease rate in bone and crown is respectively $28.7 \%$ and $65.1 \%$ under corono-apical load case, $42 \%$ and $78.6 \%$ under linguo-buccal load, and $41.7 \%$ and $79.4 \%$ under disto-mesial load. These reductions in the stress level are interesting for both mandibular bone and crown, which can offer fewer restrictions to the patient. However, the increase in compressive stress levels in the implant is large, compared to the stress reduction rate in bone and crown, but these peaks remain below the compression stress threshold of the titanium alloy.

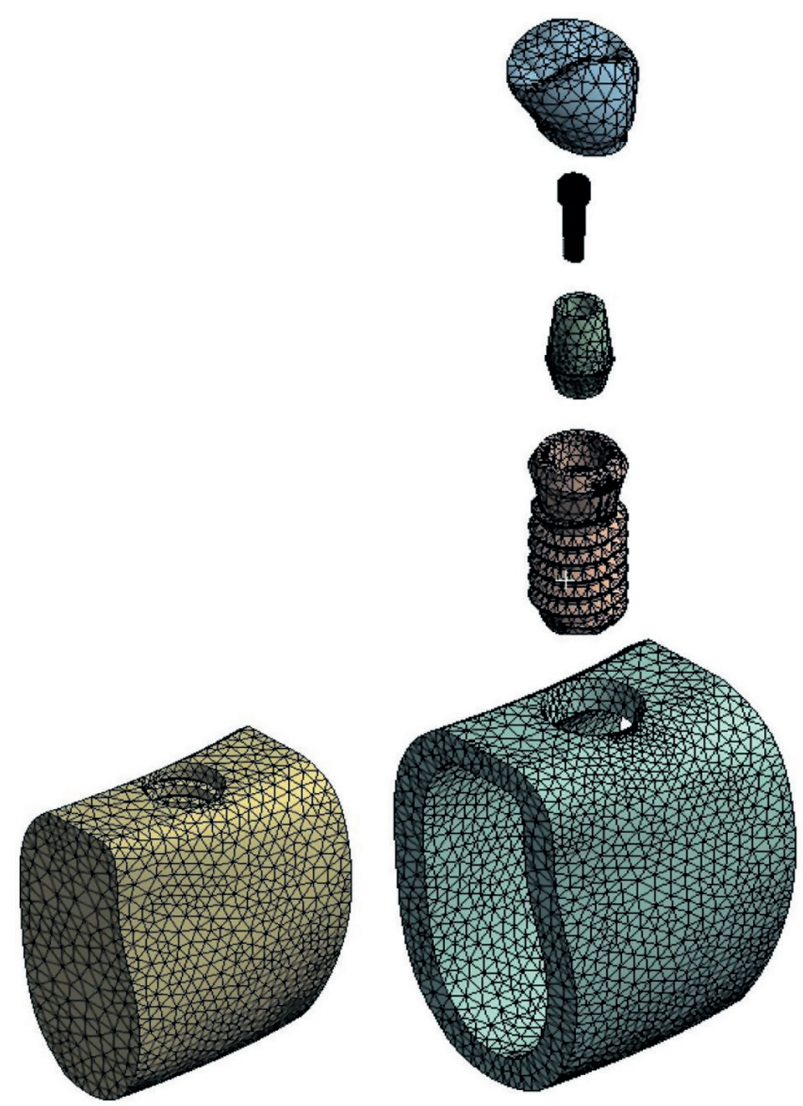

Figure 3- Bone-implant system mesh using tetrahedral quadratic elements

\begin{tabular}{|c|c|c|}
\hline Component & Elements & Nodes \\
\hline Crown & 13993 & 23903 \\
\hline Screw & 11632 & 20905 \\
\hline Abutment & 40673 & 64398 \\
\hline Implant & 14901 & 26508 \\
\hline Cortical bone & 19881 & 33349 \\
\hline Cancellous bone & 25294 & 40312 \\
\hline Complete model & 126374 & 185968 \\
\hline
\end{tabular}

Figure 4- Element and node numbers in the typical mesh implant system components

\section{DISCUSSION}

Generally, the use of soft materials as shock absorber devices designed to damp the force transfer between rigid components of a mechanical system is well known in the mechanical structures. This will keep good contact surfaces and increase the lifespan of mechanical systems by periodically replacing only the damaged joints. Even the natural tooth-bone system has a hyperelastic periodontal ligament to damp the masticatory forces towards the bone. Similarly, a very deformable elastomer, which exhibits elastic behaviour, interposed between rigid components of the implant can attenuate the load transfer towards the mandibular bone rigidly surrounding the implant by the osseointegration phenomenon. The other advantage is that the two elastomers, encapsulated within the implant system, present no risk of allergies for the patient and can be easily replaced while the implant remains undamaged.

All material components of both conventional and elastomeric models for cortical and cancellous bone were considered homogeneous, isotropic and linear elastic. The comparison of these simplified models can be considered an interesting approach to evaluate the load transfer from the implant to the bone and, consequently, the reduction rate.

With the results, we find that it was interesting to determine the stress concentration regions, namely the upper cortical neck ${ }^{4,16}$.

The neck concentration region found in our results is proven by previous studies ${ }^{11}$; this is due to the low inclination of the vertically loaded crown. However, after osseointegration, the rigid implant/ bone interface presents rising stress growing upward toward the neck ${ }^{6}$, which can cause bone deterioration at the cervical contact bone-implant ${ }^{28}$.

Whatever the type of loading, highest stress levels are located more commonly in the implant components than in the bone. This can be justified by their greater rigidity in one hand, and on the other hand the static equilibrium of forces requires an increase in stress levels in the abutment and the implant.

In a different manner, we can explain the localized stress concentrations in very small surfaces in contact with the abutment, such as around the neck or collar bone, by the force transfer from a large surface, upper crown part loaded to a narrowing of the descending section ${ }^{9,19}$. This can also be explained by the load supported by geometric edges that increase the contact pressure.

In this study, the integration of elastomers into the Osteoplant ${ }^{\circledR}$ model type provides a new design with a reduced risk of bone disease by reducing stress concentrations. For this purpose, the choice is oriented on this proposed dental implant, making 


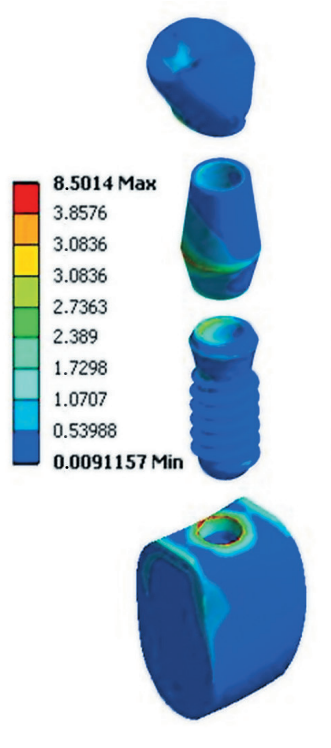

(a)

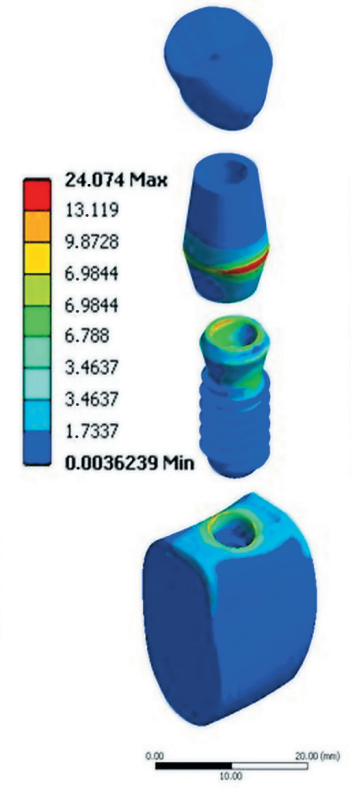

(b)

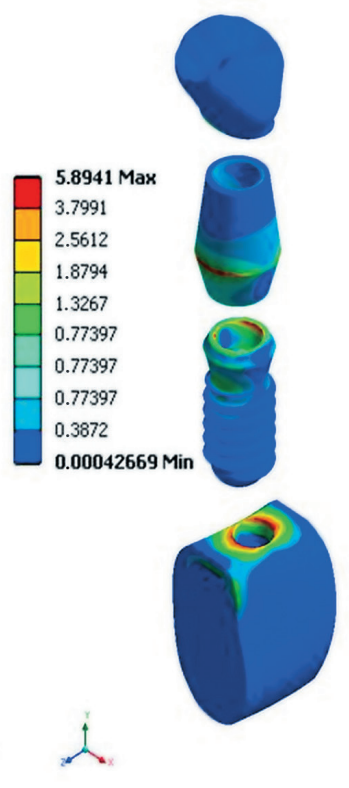

(c)

Figure 5- Von Mises stress levels in the conventional implant model components under different load cases. (a) Coronoapical load, (b) Linguo-buccal load, (c) Disto-mesial load

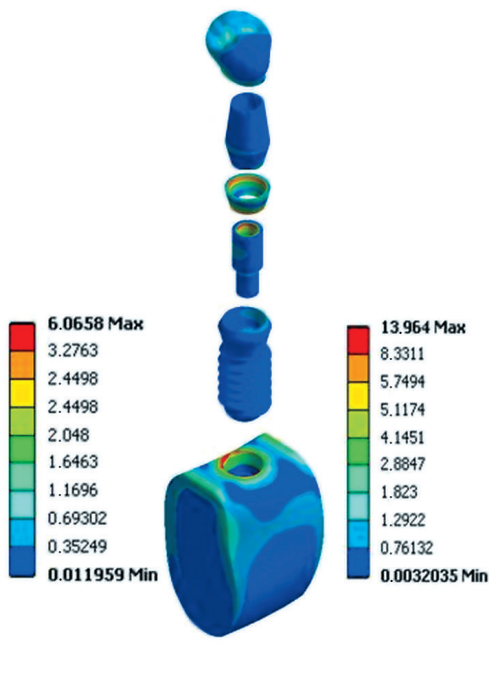

(a)

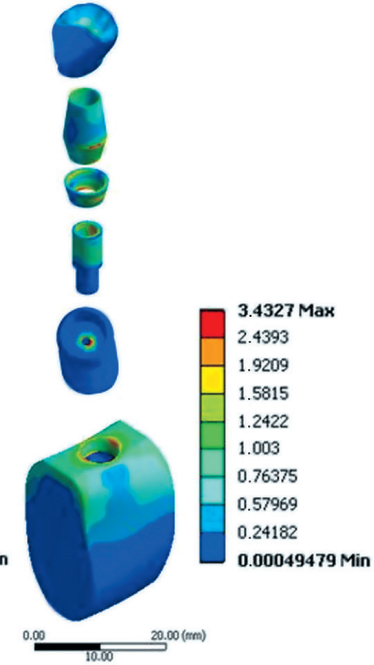

(b)

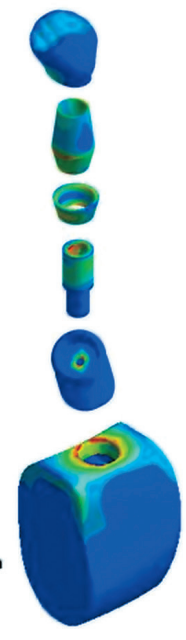

(c)

Figure 6- Von Mises stress levels in the elastomeric implant model components under different load cases. (a) Coronoapical load, (b) Linguo-buccal load, (c) Disto-mesial load

it possible to separate abutment and implant by a soft and flexible interface and to reduce the pressure of the screw head against the inner part of the abutment. Although this geometry with the boundary conditions and loading is different from reality, the results are qualitatively in agreement with previous work ${ }^{6}$.

It is also noteworthy that the highest stress value is arising from the linguo-buccal loading. This load direction can actually be just a simple component of a complex loading during mastication, which contributes to an overload in the overall stress in the mandible ${ }^{19,27}$, while it is quite possible that vertical load could indeed lead to a critical situation ${ }^{22}$.

Also, especially in the linguo-buccal load case, a recorded stress level in elastomers is approaching the material elastic limit, approximately $10 \mathrm{MPa}$. This stress absorption by elastomers in the interfaces somehow presents a kind of force transfer barrier. This break of the stiffness implies a stress decrease in the bone. Material behavior laws and the bone-implant interface chosen in this study are not real clinical situations such as osseointegration, which generally includes defects, and living tissues are inhomogeneous, anisotropic and nonlinear ${ }^{23}$. 
Table 3- Von Mises stress in the components of the two models under different load cases

\begin{tabular}{clccc}
\hline \multicolumn{1}{c}{ Model } & & Corono-apical & $\begin{array}{c}\text { Linguo-buccal } \\
\text { von Mises stress (MPa) }\end{array}$ & Disto-mesial \\
\hline Conventional model & Crown & 50.86 & 167.08 & 72.96 \\
& Abutment & 39.03 & 129.57 & 55.97 \\
& Implant & 38.48 & 114.28 & 39.69 \\
& Bone & 8.5 & 24.07 & 5.89 \\
Elastomeric model & Crown & 17.75 & 35.68 & 14.99 \\
& Abutment & 75.42 & 39.48 & 16 \\
& Elastomer 1 & 6.39 & 9.55 & 4.26 \\
& Elastomer 2 & 8.72 & 7.19 & 3.15 \\
& Implant & 231.7 & 518.91 & 343.28 \\
\hline
\end{tabular}

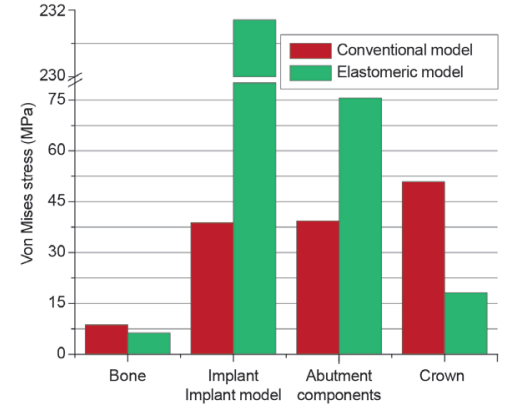

(a)

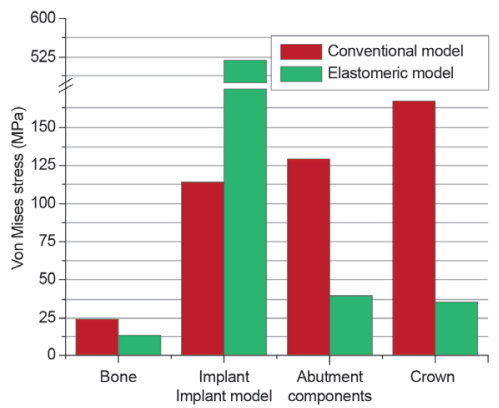

(b)

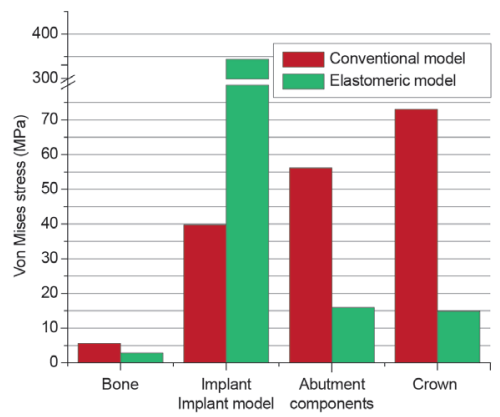

(c)

Figure 7- Von Mises stress levels for each component in the two models under different load cases. (a) Corono-apical load, (b) Linguo-buccal load, (c) Disto-mesial load

However, the proposed model provided an acceptable solution for the reduction of load transfer to the mandible. This investigation also permitted to choose how to incorporate two elastomers into the Osteoplant ${ }^{\circledR}$ implant system.

\section{CONCLUSION}

In this finite element analysis of both conventional and elastomeric implants, it was concluded that:

- The obtained stresses in bone-implant interface using the new proposed implant with elastomers are generally lower than those found with the conventional model.

- The maximum stress concentration has moved from the side of the neck of the implant (in the conventional model) to the inlet of the internal threaded hole (proposed model) because of the static equilibrium of forces in the new system.

- Relative high intensity stresses were observed in the mandibular bone in the cortical region around the implant in the two models.

- The cancellous bone had low stress levels in the two models. 
- The use of soft and flexible elastomers encapsulated in the implant with low rigidity is able to reduce or delay the load transfer to the bone.

In conclusion, the use of partial elastomeric stress absorber in this implant system provides a great interest in reducing the force transfer in the bone structure.

\section{REFERENCES}

1- Abu-Hammad OA, Harrison A, Williams D. The effect of a hidroxyapatite-reinforced polyethylene stress distributor in a dental implant on compressive stress levels in surrounding bone. Int J Oral Maxillofac Implants. 2000;15(4):559-64.

2- Babbush CA, Kirsch A, Mentag PJ, Hill B. Intramobile cylinder (IMZ) two-stage osteointegrated implant system with the intramobile element (IME): part 1. Its rationale and procedure for use. Int J Oral Maxillofac Implants. 1987;2:203-16.

3- Baggi L, Cappelloni I, Di Girolamo M, Maceri F, Vairo G. The influence of implant diameter and length on stress distribution ofosseointegrated implants related to crestal bone geometry: a three-dimensional finite element analysis. J Prosthet Dent. 2008; 100:422-31.

4- Benaissa A, Merdji A, Chikh BO, Meddah HM, Bouiadjra BB, Aminallah $\mathrm{L}$. The effect of overloads intensity on stress distribution in dental implant by 3D finite element method. J Model Simul Sys. 2012;3(1):42-50.

5- Bozkaya D, Muftu S, Muftu A. Evaluation of load transfer characteristics of five different implants in compact bone at different load levels by finite elements analysis. J Prosthet Dent. 2004;92:523-30.

6- Carvalho L, Vaz MA, Simões JA. Mandibular strains induced by conventional and novel dental implants. J Strain Anal Eng Des. 2004;39:291-7.

7- Choi $\mathrm{BH}$. Periodontal ligament formation around titanium implants using cultured periodontal ligament cells: a pilot study. Int J Oral Maxillofac Implants. 2000;15:193-6.

8- Dalkiz M, Zor M, Aykul H, Toparli M, Aksoy S. The threedimensional finite element analysis of fixed bridge restoration supported by the combination of teeth and osseointegrated implants. Implant Dent. 2002;11:293-300.

9- Djebbar N, Serier B, Bouiadjra B, Benbarek S, Drai A. Analysis of the effect of load direction on the stress distribution in dental implant. Mater Des. 2010;31:2097-101.

10- Eraslan O, Sevimay M, Usumez A, Eskitascioglu G. Effects of cantilever design and material on stress distribution in fixed partial dentures: a finite element analysis. J Oral Rehabil. 2005;32:273-8. 11- Falcón-Antenucci RM, Pellizzer EP, Carvalho PS, Goiato MC, Noritomi PY. Influence of cusp inclination on stress distribution in implant-supported prostheses. A three-dimensional finite element analysis. J Prosthodont. 2010;19:381-6.

12- Geng JP, Xu DW, Tan KB, Liu GR. Finite element analysis of an osseointegrated stepped screw dental implant. J Oral Implantol. 2004;30:223-33.

13- Geramy A, Morgano SM. Finite element analysis of three designs of an implant-supported molar crown. J Prosthet Dent. 2004;92:434-40.

14- Giesen EB, Ding M, Dalstra M, van Eijden TM. Mechanical properties of cancellous bone in the human mandibular condyle are anisotropic. J Biomech. 2001;34:799-803.

15- Heckmann SM, Winter W, Meyer M, Weber HP, Wichmann MG. Overdenture attachment selection and the loading of implant and denture-bearing area. Part 2: A methodical study using five types of attachment. Clin Oral Impl Res. 2001;12:640-7.

16- Himmlová L, Dostálová T, Kácovský A, Konvicková S. Influence of implant length and diameter on stress distribution: a finite element analysis. J Prosthet Dent. 2004;91:20-5.
17- Hoshaw SJ, Brunski JB, Cochran GV. Mechanical loading of Brånemark implants affects interfacial bone modeling and remodeling. Int J Oral Maxillofac Implants.1994;9:345-60.

18- Iranmanesh P, Abedian A, Nasri N, Ghasemi E, Khazaei S. Stress analysis of different prosthesis materials in implantsupported fixed dental prosthesis using 3D finite element method. Dental Hypotheses. 2014;5:109-14.

19- Ishigaki S, Nakano T, Yamada S, Nakamura T, Takashima F. Biomechanical stress in bone surrounding an implant under simulated chewing. Clin Oral Implants Res. 2003;14:97-102.

20- Jung YC, Han $\mathrm{CH}$, Lee KW. A 1-year radiographic evaluation of marginal bone around dental implants. Int J Oral Maxillofac Implants. $1996 ; 11(6): 811-8$.

21- Koca OL, Eskitascioglu G, Usumez A. Three dimensional finite element analysis of functional stresses in different bone locations produced by implants placed in the maxillary posterior region of the sinus floor. J Prosthet Dent. 2005;93:38-44.

22- Li T, Kong L, Wang Y, Hu K, Song L, Liu B, et al. Selection of optimal dental implant diameter and length in type IV bone: a three-dimensional finite element analysis. Int J Oral Maxillofac Surg. 2009;38:1077-83.

23- Lin D, Li Q, Li W, Duckmanton N, Swain M. Mandibular bone remodeling induced by dental implant. J Biomech. 2010;43:28793.

24- Misch CE, Bidez MW. A scientific rationale for dental implant design. In: Misch CE, ed. Contemporary implant dentistry. $3^{\text {rd }}$ ed. St Louis: Mosby; 2007. p. 329-44.

25- Natali AN, Pavan PG. A comparative analysis based on different strength criteria for evaluation of risk factor for dental implants. Comput Methods Biomech Eng. 2002;5:127-33.

26- Natali AN, Pavan PG. Numerical approach to dental biomechanics. In: Natali AN, ed. Dental biomechanics. London: Taylor \& Francis Group; 2003. p. 211-39.

27- Rangert B, Krogh PH, Langer B, Van Roekel N. Bending overload and implant fracture: a retrospective clinical analysis. Int J Oral Maxillofac Implants. 1995;10:326-34.

28- Schwartz-Arad D, Yaniv Y, Levin L, Kaffe I. A radiographic evaluation of cervical bone loss associated with immediate and delayed implants placed for fixed restorations in edentulous jaws. J Periodontol. 2004;75:652-7.

29- Yokoyama S, Wakabayashi N, Shiota M, Ohyama T. Stress analysis in edentulous mandibular bone supporting implantretained 1-piece or multiple superstructures. Int J Oral Maxillofac Implants. 2005;20:578-83. 